\title{
Effect of presentation mode on organization and recall*
}

\author{
ALIDA S. WESTMAN $\dagger$ and DENNIS J. DELPRATO \\ Eastern Michigan University, Ypsilanti, Michigan 48197
}

\begin{abstract}
Six instances of each of six taxonomic categories were presented, using photos and words, to 48 college students under incidental learning set. The Ss were unexpectedly asked to free recall the items either 3 min or 1 week after seeing them. The results showed that items in recall were grouped by taxonomic category. Picture or word presentation was used, at best, only for forming subgroups. However, items presented as photos were recalled better than those presented as words, at least after a 1 -w eek retention interval.
\end{abstract}

Two lines of research on item recall can be identified. In the first, associatively related items (e.g., animals, tools) are presented and the results show that items are recalled better if organized into groups (Thompson, Hamlin, \& Roenker, 1972). In the second, associatively unrelated items (e.g., dog, clock) are presented, and the results show that pictures are usually recalled better than words (Paivio, 1969). The present study tested whether the two lines of research could be intergrated.

The hypothesis was that if some instances of each of a number of taxonomic categories are presented as photos and some as words (a difference in presentation mode), items should be clustered by taxonomic category in recall, although presentation mode may be used to form subgroups. Furthermore, an individual item may be recalled better if it was presented as a photo than as a word. For example, if a person tries to recall the tools which were presented then, having already used the category information (the associative relatedness), he may recall photographically presented tools better.

Effectiveness for item recall of groupings used was also checked. In addition, because the better recall of pictures has been attributed to their greater imagery value (Paivio, 1969) and the effectiveness of imagery has been shown to decrease with time, half of the Ss were tested $3 \mathrm{~min}$ after exposure to the items and half were tested 1 week later in order to investigate the effect of a 1 -week retention interval.

An incidental learning task was chosen, because presentation mode (viz., sense-impression features) may be noticed more and thus be more effective with incidental than with intentional learning (Underwood, 1969).

*This research was supported by a National Science Foundation Institutional Grant to Eastern Michigan University. We thank J. Hudson and C. Wood for their help in executing the study.

TR equests for reprints should be sent to Alida S. Westman, Department of Psychology, Eastern Michigan University, Ypsilanti, Michigan 48197.

\section{METHOD}

Six common instances of each of six taxonomic categories were presented to 24 male and 24 female students enrolled in one of several introductory psychology classes. The categories used were animals, body parts, clothing, eating utensils, fruits, and tools. All instances were concrete, and those also listed by Paivio, Yuille, and Madigan (1968) were rated high in imagery value $(\overline{\mathrm{X}}=6.67)$. Each instance was presented with a slide either of the word or of a representative object shown in the center of a homogeneous white field. The words were in black capital letters produced by a children's typewriter, whereas the photos were in natural color. Color was counterbalanced across categories as much as possible. Two sets of slides were made. In the first set a random half of the instances of each category was presented as words and the remainder as photos. In the second set the manner of presenting each item was reversed.

The first set of slides was shown twice to a random half of the men and a random half of the women individually. The second set was shown to the other Ss individually. Two timers connected to a projector presented the slides for $4.4 \mathrm{sec}$. The interslide interval was $0.5 \mathrm{sec}$, and the intertrial interval was $120 \mathrm{sec}$. The random order of slides within each set differed across trials and across Ss.

The incidental learning task required that each $S$ orally rate the amount of activity of each item on the first trial and the degree of pleasantness on the second trial. A random half of the men and of the women who had been presented a particular set of slides was unexpectedly asked to orally free recall the items 3 min after exposure to them. The other Ss performed the same task, unexpectedly, 1 week later. The recall task had a 4-min time limit.

\section{RESULTS AND DISCUSSION}

The data for men and women have been combined, because none of the few sex differences was relevant.

Each S's recall was analyzed using three different organizational criteria. A score was calculated (using the procedure of Hudson \& Dunn, 1969) for clustering by taxonomic category, for clustering by presentation mode, and for separate subgroupings of photos and of words within taxonomic categories. Analysis of these scores (see Table 1) revealed that clustering by taxonomic category was significantly greater than zero 
Table 1

Mean Clustering on the Basis of Each of Three Different Organizational Criteria in Immediate and Delayed Recall

\begin{tabular}{|c|c|c|c|c|}
\hline \multirow{3}{*}{$\begin{array}{l}\text { Time of } \\
\text { Test }\end{array}$} & \multicolumn{4}{|c|}{ Basis of Clustering } \\
\hline & \multirow{2}{*}{$\begin{array}{c}\text { Taxonomic } \\
\text { Category }\end{array}$} & \multirow{2}{*}{$\begin{array}{c}\text { Presen- } \\
\text { tation } \\
\text { Mode }\end{array}$} & \multicolumn{2}{|c|}{$\begin{array}{c}\text { Within Taxonomic } \\
\text { Category }\end{array}$} \\
\hline & & & Photo & Word \\
\hline Immediate & 6.28 & -0.08 & 1.49 & 0.87 \\
\hline Delayed & 4.51 & -0.53 & 0.68 & -0.06 \\
\hline
\end{tabular}

in both immediate $[\mathrm{t}(23)=13.79, \mathrm{p}<.01]$ and delayed recall $[\mathrm{t}(23)=6.61, \mathrm{p}<.01]$, even though it decreased over the retention interval $[F(1,44)=8.28, p<.01]$. On the other hand, clustering by presentation mode was negative: although it was not significantly less than zero in immediate recall $(\mathrm{p}>.05)$, it was significantly less than zero in delayed recall $[\mathrm{t}(23)=2.62, \mathrm{p}<.05]$. In other words, recall was not organized on the basis of presentation mode.

Thus recall was grouped by taxonomic category (associative relatedness) and not by presentation mode (a feature of the representations rather than of the objects or of their meaning). This is consistent with the literature on organization of recall. Furthermore, there was subgrouping by presentation mode within taxonomic categories. In immediate recall, instances of a category presented as photos were recalled together $[\mathrm{t}(23)=5.60, \mathrm{p}<.01]$ and so were instances presented as words $[t(23)=4.07, p<.01]$. In delayed recall, this was still true with photos $[\mathrm{t}(23)=2.58, \mathrm{p}<.05]$, but it was no longer true with words $(p>.05)$. It is unclear why subgrouping by presentation mode did not continue, and further experimentation is needed to explain this.

Presentation mode did, however, influence individual item recall $[F(1,44)=22.04, p<.01]$ (see Table 2). The number of items recalled decreased from immediate to delayed tests $[F(1,44)=53.17, p<.01]$, and the interaction of Presentation Mode by Retention Interval was significant $[F(1,44)=5.76, p<.03]$. Recall of words decreased more than recall of photos. As a result more photos were recalled but in delayed recall only $(p<.01$ by Scheffés method). This is consistent with

Table 2

Mean and Standard Deviation of Number of Items Recalled in Immediate and Delayed Tests

\begin{tabular}{lrllll}
\hline & \multicolumn{4}{c}{ Presentation } & Mode \\
\cline { 2 - 3 } \cline { 5 - 6 } Time of & \multicolumn{2}{c}{ Photo } & & \multicolumn{2}{c}{ Word } \\
\cline { 2 - 3 } \cline { 5 - 6 } Test & Mean & SD & & Mean & SD \\
\hline Immediate & 12.92 & 2.52 & & 12.00 & 1.98 \\
Delayed & 9.42 & 2.54 & & 6.59 & 2.92 \\
\hline
\end{tabular}

Table 3

Correlation Between Number of Items Recalled and Clustering on the Basis of Each of Three Different Organizational Criteria in Immediate and Delayed Recall

\begin{tabular}{lcccc}
\hline & \multicolumn{3}{c}{ Basis of Clustering } \\
\cline { 2 - 5 } Time of & $\begin{array}{c}\text { Taxonomic } \\
\text { Test }\end{array}$ & $\begin{array}{c}\text { Presen- } \\
\text { tation }\end{array}$ & \multicolumn{2}{c}{$\begin{array}{c}\text { Within Taxonomic } \\
\text { Category }\end{array}$} \\
\cline { 3 - 5 } Immediate & 0.47 & Mode & Photo & Word \\
Delayed & 0.72 & -0.24 & 0.29 & 0.61 \\
\hline
\end{tabular}

the literature on recall of unrelated items which shows a superiority of photos over words (Paivio, 1969).

The effectiveness for item recall of grouping items was measured by calculating correlations between clustering by each of the three organizational criteria and number of items recalled (see Table 3 ). Clustering by taxonomic category was positively and significantly related to item recall in immediate tests $[\mathrm{t}(22)=2.50, \mathrm{p}<.05]$. This agrees with previous findings (Thompson et al, 1972). The correlation was nonsignificantly higher in delayed recall $\left[\chi^{2}(1)=1.66, p>.10\right]$. On the other hand, the correlations between subgrouping by presentations mode within taxonomic categories and number of items recalled did not differ significantly from zero $(p>.05)$, except with words in immediate recall $[\mathrm{t}(22)=3.61$, $\mathrm{p}<.01]$. Thus, subgrouping by presentation mode was not consistently effective, and why this would be so needs to be investigated. There was no relationship between clustering by presentation mode and item recall, $\mathrm{p}>.05$.

Thus, only clustering by taxonomic category was consistently and positively correlated with item recall either $3 \mathrm{~min}$ or 1 week after item presentation, even though individual instances presented as photos were recalled better than those presented as words. It seems that the two lines of research are interrelated as hypothesized.

\section{REFERENCES}

Hudson, R. L., \& Dunn, J. E. A major modification of the Bousfield (1966) measure of category clustering. Behavior Research Methods \& Instrum entation. 1969, 1, 110-111.

paivio A. Mental imagery in associative learning and memory. Psychological Review, 1969, 76, 241-263.

Paivio, A., Yuille, J. C., $\star$ Madigan, S. A. Concreteness, imagery, and meaningfulness values for 925 nouns. Journal of Experimental Psychology Monographs, 1968, 76 (1, part 2). Thompson, C. P., Hamlin, V. J., \& Roenker, D. L. A comment on the role of clustering in recall. Journal of Experimental Psychology, 1972, 94, 108-109.

Underwood, B. J. Attributes of memory. Psychological Review, 1969, 76, 559-573.

(R eceived for publication July 27, 1974.) 